\title{
Pre and postharvest evaluation of hydroponically grown tomato at different maturity stages
}

\author{
Hafiz Nazar Faried ${ }^{1 *}$, Zeeshan Haider ${ }^{1}$, Ishtiaq Ahmed Rajwana ${ }^{1}$, Ali
} Asad Bahar ${ }^{1}$, Shahzad Ahmed ${ }^{2}$, Sami Ullah ${ }^{1}$, Kashif Razzaq ${ }^{1}$, Gulzar Akhtar ${ }^{1}$, Muhammad Amin ${ }^{1}$, Ambreen Naz ${ }^{3}$, Arslan Mehmood ${ }^{1}$, Abdul Manan Athar ${ }^{1}$ and Muhammad Shahzad Zafar ${ }^{4}$

1. Department of Horticulture, MNS University of Agriculture, Multan, Pakistan

2. Department of Agri-engineering, MNS University of Agriculture, Multan, Pakistan

3. Department of Food Science and Technology, MNS University of Agriculture, Multan, Pakistan

4. Mango Research Station, Shujabad, Pakistan

*Corresponding author's email: nazar.farid@mnsuam.edu.pk

Citation

Hafiz Nazar Faried, Zeeshan Haider, Ishtiaq Ahmed Rajwana, Ali Asad Bahar, Shahzad Ahmed, Sami Ullah, Kashif Razzaq, Gulzar Akhtar, Muhammad Amin, Ambreen Naz, Arslan Mehmood, Abdul Manan Athar and Muhammad Shahzad Zafar. Pre and postharvest evaluation of hydroponically grown tomato at different maturity stages. Pure and Applied Biology. Vol. 11, Issue 3, pp704-708. http://dx.doi.org/10.19045/bspab.2022.110071

\begin{tabular}{|c|c|c|c|}
\hline Received: 30/07/2021 & Revised: 20/09/2021 & Accepted: 23/09/2021 & Online First: 07/10/2021 \\
\hline
\end{tabular}

\section{Abstract}

Tomato is a valuable crop preferably grown in greenhouse under soil and soilless cultivation system. Tomato demand in the country has been increasing at $7.3 \%$ annually while the yield is 9.5 tons $\mathrm{ha}^{-1}$ that is not only stagnant but also the only $25 \%$ of the global average (38-ton per ha). Therefore, one needs to find the alternate high production technologies like soilless greenhouse farming. In this regard, a pre- and post-harvest studies were planned to evaluate the performance of beefsteak (cv Badia) and plum (cv Sahil) tomatoes grown in soilless cultivation system under partially controlled greenhouse. Additionally, the fruits were harvested at three maturity stages ( $\mathrm{M}_{1}$ : Mature green, $\mathrm{M}_{2}$ : Turning and $\mathrm{M}_{3}$ : Ripped tomatoes) for its shelf-life testing. Different morpho-physio-biochemical attributes were recorded as per the requirement. Pre-harvest results indicated that the cultivar Badia performed better than Sahil in number of leaves, inter-nodal distance and fruit size, photosynthetic rate, transpiration rate, stomatal conductance, sub-stomatal $\mathrm{CO}_{2}$, and water use efficiency. However, cultivar Sahil performed better in total soluble solids $\left(\mathrm{TSS}^{\circ}\right)$, ascorbic acid and total acidity.

Keywords: Lycopersicon esculentum; Photosynthesis; Soilless; Vitamin C

\section{Introduction}

Tomato is a popular vegetable in Pakistan and widely utilizes for salads and cooking. It's a rich source of minerals and vitamins [1]. However, antioxidant activity depends on variety, growing conditions, and ripening stages [2]. In Pakistan, tomato is cultivated on an area of 55,260 ha with an annual production of 0.56 million tons during kharif and rabi seasons (protected off season). Additionally, Pakistan exported 29,160 tons worth 1161 million PKR while imported 182153 tons worth 3676 million PKR during 2019 [3]. Being tender, tomato crop is more prone to soil and air borne biotic and abiotic (temperature, drought, salinity etc.) stresses, thereby negatively affecting its growth, development, yield, and quality. Besides, market demand couldn't be 
fulfilled mostly due to poor cultivation techniques, inappropriate cultivar selection, insufficient plant nutrition, adverse climatic conditions, pest, and disease infestation. Moreover, the demand for tomato and its products has been increasing at a rate of 7.3\% per annum, much higher than the current production. Pakistan earns only $28 \%$ of the world average export price suggesting great challenges in improving tomato value chain. The country exports less than $1 \%$ of its production while the world average export-production ratio is 4.7\%. Pakistan has great potential to improve its export-production ratio because of its lower farm gate prices than the world average. In this connection, Pakistan may become an exporter of tomato by adopting new techniques to improve the existing practices and move towards the protected cultivations and production [4].

Hydroponic technology has been adopted widely as an industrial agriculture and NASA declares it a cultivation system for space stations [5]. Hydroponic systems have different supporting medium for growing the plant roots like coconut coir, peat moss, vermiculite and rock wool. Aggregate systems have a solid medium of support. Hydroponic growing media are designed porous for excellent retention of air and water. Healthy plant-roots are developed by good breath [6]. It does not harm our environment as runoff fertilizer enriched water is reutilized. It is useful technology particularly for drought and salinity affected areas. Water and nutrients are used efficiently with an appropriate regulation of electrical conductivity (EC) and $\mathrm{pH}$ of the nutrient solution along-with optimum growing temperature. Therefore, soilless production system provides an optimum environment for growth and progress of plants which results in higher yield and value as compared to traditional production methods [7]. Mostly, high value vegetables (e.g. tomato, pepper, cucumber, greens) ate grown under hydroponic cultivation system. Most of the vegetables are perishable. Poor handling and transport system affects produce quality, thereby higher postharvest losses which are 24-40\% in developing countries while $2-20 \%$ in advanced countries [8]. Tomato crop have a short life spam due to higher water contents and respiration during its ripening period [9]. Therefore, reduction in postharvest losses of tomato crop is required for improved food security particularly in emerging countries [10]. In developing countries like Pakistan, a unified and comprehensive approach is required for pre- and post-harvest studies of high value crops like tomato (beefsteak and plum) particularly under soilless greenhouse cultivation system for higher and quality production per unit area to fulfill indigenous sustainable requirement and foreign exchange earnings. In this regard, a soilless tomato cultivation study was planned to compare yield and shelf quality of beefsteak and plum tomato under semiarid climate of the South Punjab.

\section{Materials and Methods}

The study was conducted at Latitude of $30^{\circ}$ $8^{\prime} 26.93$ "N and longitude of $71^{\circ} 26^{\prime} 35.43^{\prime \prime} \mathrm{E}$ in a hydroponic unit located at University Research Farm, MNS-University of Agriculture, Multan. The study was aimed to evaluate the performance of hydroponically grown tomato cultivars $\left(\mathrm{CV}_{1}\right.$ : Badia and $\mathrm{CV}_{2}$ : Sahil $)$ at three maturity stages $\left(\mathrm{T}_{1}\right.$ Mature green, $\mathrm{T}_{2}$ Turning and $\mathrm{T}_{3}$ Ripped) with factorial arrangement under complete randomized design (CRD) replicated thrice. An economical nutrient recipe with a defined fertigation schedule was developed to ensure the appropriate provision of water and nutrient as per growth stages. Following temperature and relative humidity were observed during the entire study (Table 1).

Pre-harvest data includes germination percentage, number of leaves, number of clusters, inter nodal distance $(\mathrm{cm})$, shoot fresh and dry weight $(\mathrm{g})$, number of fruits per cluster, and fruit size $(\mathrm{cm})$. Moreover, gaseous exchange parameter includes photosynthesis rate $(P n)$, transpiration rate 
$(E)$, stomatal conductance $(g s)$ and substomatal $(C i)$ were assessed from top $3^{\text {rd }}-4^{\text {th }}$ intact tomato plant's leaf from 11:30 am to 2:30 pm with the help of CIRAS-3 Portable Photosynthetic System SW Version 2.00 Console Serial Number, C3F0255 by PP System, Amesbury, MA, USA. Besides this, post-harvest analysis includes titratable acidity (TA \%), total soluble solids (TSS), and vitamin C (mg $100 \mathrm{~g}^{-1}$ of juice) which were carried out in postharvest science and technology lab, central lab system. Collected data was subjected to analysis of variance (ANOVA) by using Statistix 8.1.

Table No 1. Average Maximum and Minimum Temperature $\left({ }^{\circ} \mathrm{C}\right)$ and Relative humidity (\%) of the Greenhouse during the Crop Season

\begin{tabular}{|c|c|c|c|c|}
\hline & \multicolumn{2}{|c|}{ Temperature $\left({ }^{\circ} \mathbf{C}\right)$} & \multicolumn{2}{c|}{ Relative Humidity (\%) } \\
\hline Month & Min & Max & Min & Max \\
\hline January & 22.6 & 27.8 & 60.1 & 64.6 \\
\hline February & 26.3 & 31.7 & 61.8 & 65.1 \\
\hline March & 29.4 & 30.8 & 64.2 & 67.4 \\
\hline April & 32.7 & 34 & 63.6 & 68.3 \\
\hline May & 33.2 & 36.1 & 66.7 & 71.2 \\
\hline
\end{tabular}

\section{Results and Discussion}

Pre-harvest results showed that germination percentage was found $100 \%$ in both cultivars. The cultivar Badia attained maximum number of leaves (43) and internodal distance $(2.67 \mathrm{~cm})$. However, the cultivar Sahil attained maximum number of clusters (13), number of fruits per cluster (6.86), thereby the total number of fruits per plant (66). However, maximum fruit size was attained by cultivar Badia $(82.13 \mathrm{~mm})$ followed by Sahil (37.88 mm) (Table 2). Additionally, the cultivar Badia showed maximum fruits size. The results are in line to the findings of other studies [11] which might be associated that reduced internodal distance and number of clusters promotes fruit size. Similarly, in this connection, gaseous exchange attributes demonstrated that cultivar Badia attained maximum photosynthetic rate (10.03), transpiration rate (18.98), stomatal conductance (163.71), sub stomatal conductance (256.71), water use efficiency (5.97) and vapor pressure deficit (3.05) as compared to cultivar Sahil (Table 3). Irrespective to all this, post-harvest analysis results showed a significant difference among three maturity stages (Green, Turning and Red) of the tomato cultivars. The cultivar Badia showed that the titratable acidity (TA) showed a decreasing trend from green stage to red. Maximum range of TA was observed at green maturity stage (0.35) and minimum was observed at red maturity stage (0.26). Total soluble solids (TSS) and vitamin $\mathrm{C}$ were also influenced at different maturity stages (Table 4). Vitamin C showed an increasing trend from green to red maturity stage. The maximum increase of vitamin $\mathrm{C}$ was in red maturity stage (120 $\mathrm{mg} / 100 \mathrm{ml}$ ). The amount of Vitamin $\mathrm{C}$ ranged from 60 to 120 among three maturity stages (Green, Turning and Red) of Badia cultivar (Table 4). Similarly, the cultivar Sahil also depicted a decreasing trend in titratable acidity (TA) from green to red stage. Moreover, the total soluble solids (TSS) and vitamin C of cultivar Sahil were also influenced at different maturity stages (Table 4). TSS contents were found higher at red maturity stage (3.53) while lower at turning stage (3.13). Our results are in lined to the findings of [12] they reported that TSS content in fruits of tomatoes ranged between 3.6 to $5.7^{\circ} \mathrm{Brix}$, respectively. Similarly, vitamin $\mathrm{C}$ contents were found higher at red maturity stage (134), followed by turning stage (108) whereas lowest reading was recorded at green stage (103) (Table 4). 
Table 2. Morphological Attributes

\begin{tabular}{|c|c|c|c|c|c|c|c|}
\hline Cultivars & $\begin{array}{c}\text { Emergen } \\
\text { ce \% }\end{array}$ & $\begin{array}{c}\text { No of } \\
\text { leaves }\end{array}$ & $\begin{array}{c}\text { No of } \\
\text { cluster }\end{array}$ & $\begin{array}{c}\text { *IND } \\
(\mathbf{c m})\end{array}$ & $\begin{array}{c}\text { No of } \\
\text { fruit/clust } \\
\text { er }\end{array}$ & $\begin{array}{c}\text { Fruit size } \\
(\mathbf{m m})\end{array}$ & $\begin{array}{c}\text { No of } \\
\text { Fruit / } \\
\text { plant }\end{array}$ \\
\hline Badia & $100 \mathrm{a}$ & $43.5 \mathrm{a}$ & $10.5 \mathrm{~b}$ & $2.67 \mathrm{a}$ & $4.28 \mathrm{~b}$ & $82.13 \mathrm{a}$ & $38 \mathrm{~b}$ \\
\hline Sahil & $100 \mathrm{a}$ & $38.5 \mathrm{~b}$ & $13 \mathrm{a}$ & $2.53 \mathrm{~b}$ & $6.86 \mathrm{a}$ & $37.88 \mathrm{~b}$ & $66 \mathrm{a}$ \\
\hline
\end{tabular}

*IND Internodal distance

Table 3. Physiological attributes of tomato leave of top third leave

\begin{tabular}{|c|c|c|c|c|c|c|}
\hline Varieties & $\begin{array}{c}P n(\mu \mathrm{mol} \\
\left.\mathrm{CO}_{2} \mathrm{~m}^{-2} \mathrm{~s}^{-1}\right)\end{array}$ & $\begin{array}{c}E(\mathbf{m m o l} \\
\left.\mathrm{H}_{2} \mathbf{O ~ m}^{-2} \mathbf{s}^{-1}\right)\end{array}$ & $\begin{array}{c}g s(\mathbf{m m o l} \\
\left.\mathbf{H}_{2} \mathbf{O ~ m}^{-2} \mathbf{s}^{-1}\right)\end{array}$ & $\begin{array}{c}\mathrm{Ci}(\boldsymbol{\mu \mathrm { mol }} \\
\left.\mathrm{mol}^{-1}\right)\end{array}$ & $\begin{array}{c}\text { WUE }(\mathbf{m m o l} \\
\left.\mathrm{CO}_{2} \mathrm{~mol}^{-1} \mathrm{H}_{2} \mathrm{O}\right)\end{array}$ & $\begin{array}{r}\text { VPD } \\
(\mathbf{k P a})\end{array}$ \\
\hline Badia & $10.03 \mathrm{a}$ & $18.98 \mathrm{a}$ & 163 & $7 \mathrm{a}$ & $5.97 \mathrm{a}$ & $3.05 \mathrm{a}$ \\
\hline Sahil & $8.88 b$ & $12.69 \mathrm{~b}$ & $123.38 b$ & $231.71 b$ & $3.97 \mathrm{~b}$ & $2.65 \mathrm{~b}$ \\
\hline
\end{tabular}

*Photosynthesis Rate $(A)$, Transpiration Rate $(E)$, Stomatal Conductance $(g s)$, Sub-Stomatal $\mathrm{CO}_{2}(\mathrm{Ci})$, Water use efficiency $(W U E)$, Vapor Pressure Deficit $(V P D)$

Table 4. Biochemical Parameters

\begin{tabular}{|c|l|c|c|c|}
\hline CVs & \multicolumn{1}{|c|}{ Observation } & Green & Turning & Red \\
\hline \multirow{3}{*}{ Badia } & Titrable Acidity (TA) $(\%)$ & 0.35 & 0.27 & 0.26 \\
\cline { 2 - 5 } & Total Soluble Solids (TSS) $\left({ }^{\circ}\right.$ Brix) & 2.3 & 3.2 & 4.5 \\
\cline { 2 - 5 } & Vitamin C (mg/100g) & 62 & 82 & 120 \\
\hline \multirow{2}{*}{ Sahil } & Titrable Acidity (TA) $(\%)$ & 0.25 & 0.21 & 0.23 \\
\cline { 2 - 5 } & Total Soluble Solids (TSS) $\left({ }^{\circ}\right.$ Brix) & 3.46 & 3.13 & 3.53 \\
\cline { 2 - 5 } & Vitamin C (mg/100g) & 103 & 108 & 134 \\
\hline
\end{tabular}

\section{Conclusion}

Pre- and post-harvest analysis of hydroponically grown tomato cultivars (Badia and Sahil) elaborating that cultivar Badia performed well in improving the physiological attributes, number of leaves and fruit size. However, the cultivar Sahil performed better in increasing the number of clusters, number of fruits per cluster, and post-harvest attributes (TSS and ascorbic acid).

\section{Authors' contributions}

Conceived and designed the experiments: HN Faried, IA Rajwana, S Ahmed, K Razzaq \& M Amin, Performed the experiments: Z Haider, A Mehmood, AM Athar \& A Naz, Analysed the data: G Akhtar \& S Ullah, Contributed reagents/ materials/ analysis tools: A Naz \& MS Zafar, Wrote the paper: HN Faried, Zeeshan Ahmad \& AA Bahar.

\section{References}

1. Frusciante LB, Barone D, Carputo MR, Ercolano F, Della R \& Esposito S (2000). Evaluation and use of plant biodiversity for food and pharmaceuticals. Fitoterapia 71: 66-72.

2. Leonardi CP, Ambrosino F, Esposito \& Fogliano V (2000). Antioxidant activity and carotenoid and tomatine contents in different typologies of fresh consumption tomatoes. J Agric Food Chem 48: 4723-4727.

3. MNFSR. (2017). Fruit, Vegetables and Condiments Statistics of Pakistan 20132014. Govt. of Pakistan, Ministry of National Food Security and Research, Islamabad.

4. Tahir A, Shah H, Sharif M, Akhtar W \& Akmal N (2012). An overview of tomato economy of Pakistan: comparative analysis. Pak J Agric Res 25: 288-295. 
5. Plooy Du, Maboko CP, Van den Heever MM \& Chiloane S (2012). Research and technology transfer by Agricultural Research Council to sustain South African hydroponic industry. Acta Hortic 947: 147-151.

6. Lakkireddy K \& Kondapalli K (2012). Role of Hydroponics and Aeroponics in Soilless Culture in Commercial Food Production.

7. Maboko MM, du Plooy CP \& Bertling I (2009). Comparative performance of tomato on soilless vs in-soil production systems. Acta Hortic 843: 319-326.

8. Rosa S (2006). Postharvest management of fruit and vegetables in the Asia-Pacific region/Asian Productivity Organization. Food and Agricultural Organization (FAO).

9. Ullah J (2009). Storage of fresh tomatoes to determine the level of
$(\mathrm{CaCl} 2)$ coating and optimum temperature for extended shelf life, Asian Institute of Technology Bangkok, Thailand.

10. Kader AA (2005). Increasing food availability by reducing postharvest losses of fresh produce. Inter Postharvest Symposium 682: 21692176.

11. Saleem MY, Asghar M, Haq MA, Rafique T, Kamran A \& Khan AA (2009). Genetic analysis to identify suitable parents for hybrid seed production in tomato (Lycopersicon esculentumL.). Pak J Bot 41(3): 11071116.

12. Dar RA, Sharma JP, Nabi A \& Chopra S (2012). Germplasm evaluation for yield and fruit quality traits in tomato (Solanum lycopersicon L.). Afr J Agri Res 7: 6143-6149. 